\title{
ENERGY STUDY OF A HEAT PUMP USED FOR AIR HEATING AND DEHUMIDIFICATION
}

\author{
N. L. Maia ${ }^{a}$, \\ M. L. Diniz ${ }^{a}$, \\ J. M. A. M. Gurgel ${ }^{\mathrm{a}}$, \\ R. R. Gondim a \\ M. Carvalho ${ }^{\mathrm{a}}$, \\ and M. R. Luiz \\ ${ }^{\text {a }}$ Federal University of Paraíba, \\ Center of Alternative and Renewable Energy, \\ Department of Renewable Energy Engineering. \\ Caixa Postal 5115, CEP 58.059-970. Cidade \\ Universitária, João Pessoa, Paraíba, Brazil. \\ naylobo@gmail.com \\ bState University of Paraíba, \\ Science and Technology Center, \\ Campina Grande, Paraíba, Brasil. \\ Received: September 08, 2015 \\ Revised: October 08, 2015 \\ Accepted: November 09, 2015
}

\section{NOMENCLATURE}

CM Conservation of Mass

Ek Kinetic energy

Ep Potential energy

FLT First Law of Thermodynamics

h Enthalpy $(\mathrm{kJ} / \mathrm{kg})$

$\dot{m}$ Mass flow, kg/s

$\mathrm{P} \quad$ Pressure $(\mathrm{kPa})$

$\dot{Q} \quad$ Heat flow, kJ/s

$\mathrm{R} \quad$ Gas constant, $(\mathrm{kJ} / \mathrm{kg} \cdot \mathrm{K})$

$\dot{W} \quad$ Work, kJ/s

\section{Greek symbols}

\section{$\Delta \quad$ Variation}

$\omega \quad$ Absolute humidity, $\mathrm{kg}_{\mathrm{H}_{2} \mathrm{O}} / \mathrm{kg}_{\text {dry air }}$

$\phi \quad$ Relative humidity, \%

\section{Subscripts}

$0 \quad$ Ambient

1 Inlet of evaporator

2 Outlet of evaporator

3 Inlet of condenser

4 Outlet of condenser

A Outlet of compressor

B Outlet of condenser
ABSTRACT

Heat pump assisted dryers can realize considerable savings of primary energy as compared with conventionally-heated air drying. This manuscript analyzes the design and construction aspects of a heat pump assisted dryer for biological products. The performance of the heat pump is investigated through an energy analysis, carried out under operating conditions of practical interest. The system is operated using R22 and is also evaluated with respect to the coefficient of performance (COP). Although the current trend is to invest in low-energy, low-carbon technologies, heat pump assisted dryers remain underexplored in the industrial sector due to its more complex operation.

Keywords: heat pumps, energy analysis, dryer system, heat recovery, drying of biological products

$\begin{array}{ll}\text { C } & \text { Outlet of expansion valve } \\ \text { comp } & \text { Compressor } \\ \text { D } & \text { Entrance of compressor } \\ \text { fan } & \text { Fan } \\ \text { gas } & \text { Dry air } \\ \text { R-22 } & \text { Refrigerant } \\ \text { vap } & \text { Vapor }\end{array}$

\section{INTRODUCTION}

In recent decades, new technologies with improved energy efficiency and less environmental damages associated are desirable, especially those connected to renewable sources. In this context, the heat pump is a refrigeration machine that operates according to a thermodynamic compression refrigeration cycle, transferring heat from a low temperature source to a high temperature source at the expense of work obtained, normally, by the consumption of electricity. It emerges as an alternative of energy savings in drying processes due to its ability to reuse the waste heat from other processes, mainly industrial, and greater control in drying conditions, such as temperature and humidity, resulting in a final product with higher quality.

Heat pump applications cover several sectors: residential, commercial and industrial. Castell-Palou and Simal (2011) dried cheese cubes using a 
convective heat pump at different temperatures, evaluating the effect of drying air temperature on drying kinetics and also proposed a diffusion mathematical model for simulation. Yang et al.(2013) carried out a comparative simulation between different intermittent heat pumps with respect to moisture diffusion, energy consumption and drying time on cabbage seeds through numerical simulation and experiments. Heat pump dryers also used in other drying processes, such as apples, herbs, cocoa beans, chili and marine products (Fatouh et al., 2006, Aktaş et al., 2009,Daghigh et al., 2010, Artnaseaw et al., 2010, Hii et al., 2012).

The current global energy crisis has resulted in the development of new technologies, and also in a growing concern with the study of systems providing the best final result with low consumption of energy. In these aspects, the energy analysis is based on the First Law of Thermodynamics and focuses on a quantitative study of the different forms of energy involved in the processes. In a heat pump study, this analysis provides an evaluation between the quantity of energy consumed as work and the amount of energy in the form of heat obtained as a result, enabling for a comparative study of several drying systems.

This paper focuses on an experimental and theoretical study, carried out through an energy analysis, of a heat pump used in the drying of biological products. The heat pump presents as singularity: the heat released by the compressor is harnessed and added to condenser heat, helping heat the air, contributing to a better efficiency of the drying system.

\section{EXPERIMENTS}

\section{General aspects of heat pump}

The experimental apparatus was developed at the Solar Energy Laboratory of the Federal University of Paraíba (city of João Pessoa, Northeast Brazil), where the experiment was also conducted. An initial setup was built by Luiz (2007), which was improved and taken a step further herein. The compressor of the experimental apparatus in the initial setup was replaced by one that consumes less power, the fan is now operating with variable frequency (enabling variation of air velocity, providing different work conditions), and the manometers installed in the initial configuration were replaced by line pressure gauges, providing more precise data. The heat pump setup consists of a chamber where the product undergoes the drying process and a compartment where the heat pump is located. The equipment used in the experiment consists only of the heat pump, featuring an open system (Fig. 1) where the hot air returns to the atmosphere without crossing the drying chamber.

The heat pump consists of (Fig. 1): a fan (1), condenser (2), compressor (3), evaporator (4) and an expansion valve (5). The refrigerant used in the system is R-22. Two PVC pipes were installed the entrance and exit of the system through which the air passes. The air is sucked by the fan, then it is dehumidified by the evaporator, to a temperature lower than dew point temperature, condensing the water present in the air as vapor state. The dehumidified air passes through the compressor and condenser, absorbing the heat released from both surfaces and is heated. Finally, the air is released to the atmosphere (open system) or to the drying chamber (closed system), being heated and dehumidified. The dehumidification process causes a decrease in absolute humidity and an increase in relative humidity. In the heating process, the relative humidity of the air increases again.

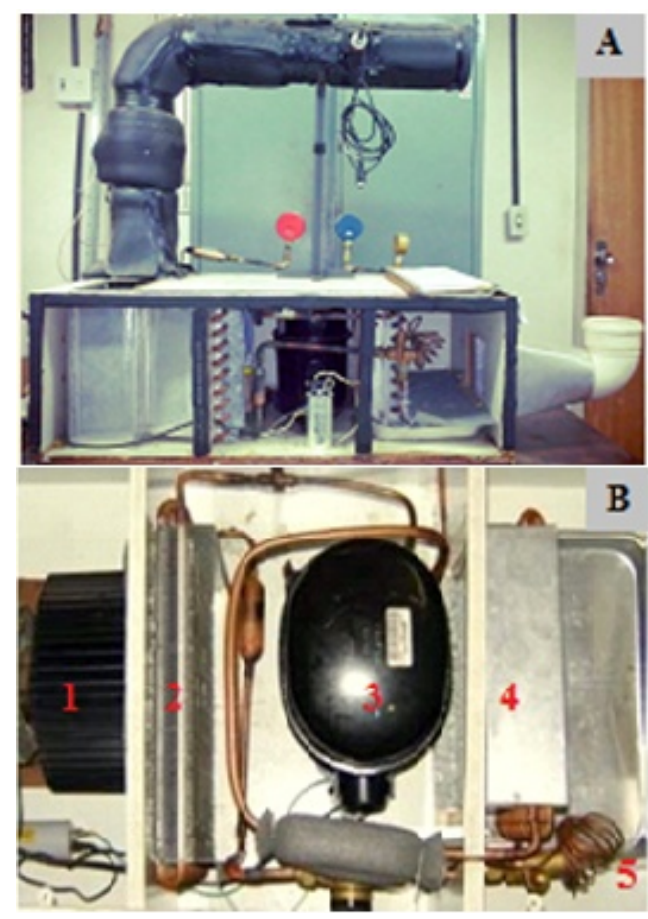

Figure 1. Open configuration used in the experiment (A) and components of the heat pump (B).

The instrumentation consists of anemometers installed in the PVC tubes (corresponding to the inlet of the evaporator and outlet of the condenser, measuring air speed), PT $100 \Omega$ thermometers (at local atmospheric pressure, also installed in the PVC tubes to measure dry and wet bulb temperatures, allowing the determination of the thermodynamic state of the air, and in the inlet and outlet of the evaporator and condenser), temperature sensors in the system piping (inside which the refrigerant flows), and two line pressure gauges (Instruterm PS100, at the entrance of the condenser and exit of the evaporator). The PT $100 \Omega$ sensors were installed in a data acquisition device and LabView software 9.0 (<http://www.ni.com/labview/applications/instrument -control/pt/> Accessed on 02 October, 2014) was 
used to register the average temperatures. Condensed water in the evaporator was collected in a tray and measured in a beaker, and the pressures were measured with a digital manometer (Instruterm MVR87) throughout the system. The compressor was thermally isolated from the evaporator. Relative humidity was also measured, enabling determination of absolute humidity.

\section{Energy Analysis}

A scheme of the heat pump is shown in Fig. 2, with the location of control volumes presented in Figures 3 and 4. The letters A, B, C and D represent the refrigerant cycle, while numbers $(1,2,3,4)$ represent the air process. All processes are considered stationary.

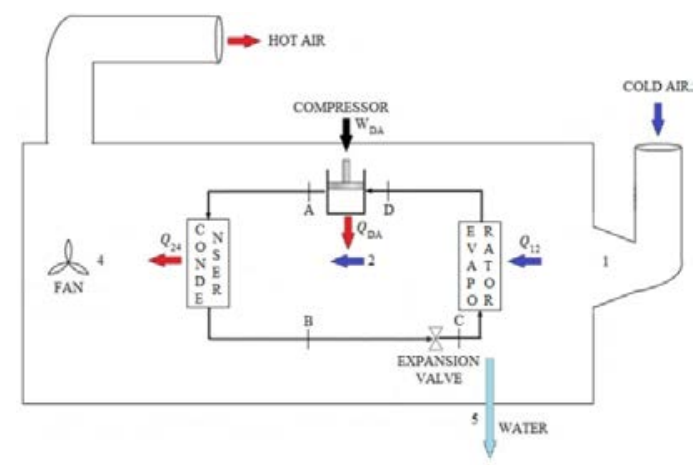

Figure 2: Heat pump scheme.

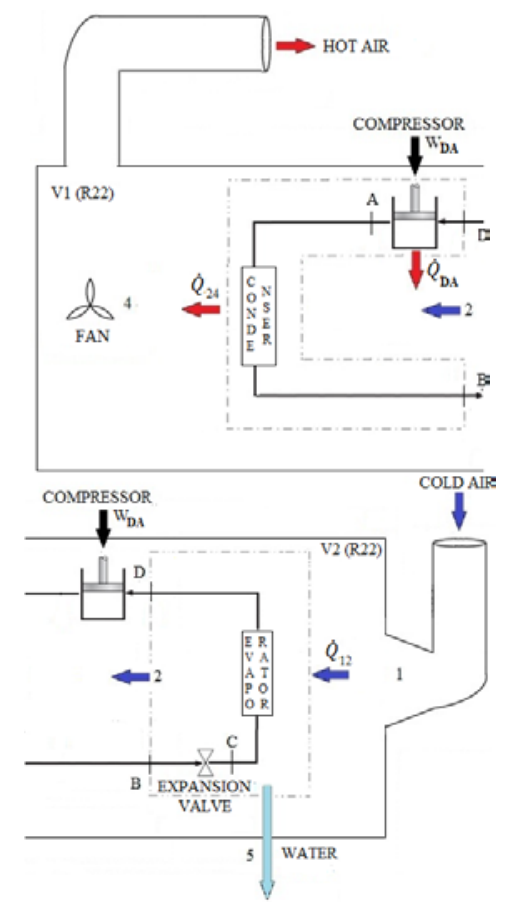

Figure 3. Control volumes V1 (top) and V2 (bottom) for R22.

According to Conservation of Mass (CM) for R22 in V1:

$$
\dot{\mathrm{m}}_{\mathrm{D}}=\dot{\mathrm{m}}_{\mathrm{A}}=\dot{\mathrm{m}}_{\mathrm{B}}=\dot{\mathrm{m}}_{\mathrm{R}-22}
$$

In Eq. (1), $\dot{\mathrm{m}}_{\mathrm{D}}$ is the flow rate in the entrance of the compressor, $\dot{\mathrm{m}}_{\mathrm{A}}$ is the flow rate in the outlet of the compressor, $\dot{\mathrm{m}}_{\mathrm{B}}$ is the flow rate in the outlet of the condenser, and $\dot{\mathrm{m}}_{\mathrm{R}-22}$ is the flow rate of the refrigerant. According to the First Law of Thermodynamics (FLT, considering the variation of potential and kinetic energies to be negligible: $\Delta \mathrm{Ep} \cong$ 0 and $\Delta \mathrm{Ek} \cong 0$, and a stationary energy process):

$$
\dot{\mathrm{Q}}_{\mathrm{DA}}=\dot{\mathrm{W}}_{\mathrm{DA}}+\dot{\mathrm{m}}_{\mathrm{R}-22}\left(\mathrm{~h}_{\mathrm{A}}-\mathrm{h}_{\mathrm{B}}\right)
$$

In Eq. (2), $\dot{Q}_{D A}$ is the heat released by the surface of the compressor, $\dot{W}_{D A}$ is the work of the compressor, $\mathrm{h}_{\mathrm{B}}$ is the enthalpy of the refrigerant in the state $A$ and $h_{D}$ is the enthalpy of the refrigerant in the state $\mathrm{D}$. The heat released by the surface of the condenser, according the FLT, is:

$$
\dot{\mathrm{Q}}_{\mathrm{AB}}=\dot{\mathrm{m}}_{\mathrm{R}-22}\left(\mathrm{~h}_{\mathrm{B}}-\mathrm{h}_{\mathrm{A}}\right)
$$

In Eq. (3), the variation of potential and kinetic energies is negligible: $\Delta \mathrm{Ep} \cong 0$ and $\Delta \mathrm{Ek} \cong 0$, and the energy process is stationary. The enthalpy of the refrigerant in the state $B$ is represented by $h_{B}$. The heat transfer between the states $D$ and $B$ is $\dot{\mathrm{Q}}_{\mathrm{DB}}=\dot{\mathrm{Q}}_{\mathrm{DA}}+\dot{\mathrm{Q}}_{\mathrm{AB}}$ or, according to FLT:

$$
\begin{aligned}
\dot{\mathrm{Q}}_{\mathrm{DB}} & =\dot{\mathrm{W}}_{\mathrm{DA}}+\dot{\mathrm{m}}_{\mathrm{B}} \mathrm{h}_{\mathrm{B}}-\dot{\mathrm{m}}_{\mathrm{D}} \mathrm{h}_{\mathrm{D}} \\
& =\dot{\mathrm{W}}_{\mathrm{DA}}+\dot{\mathrm{m}}_{\mathrm{R}-22}\left(\mathrm{~h}_{\mathrm{B}}-\mathrm{h}_{\mathrm{D}}\right)
\end{aligned}
$$

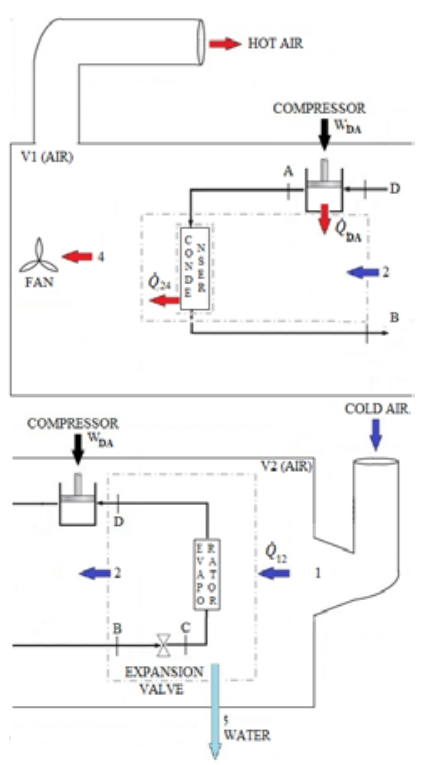

Figure 4. Control volumes V1 (top) and V2 (bottom) for air. 
Considering the heat released by the refrigerant in the compressor and condenser absorbed as by the air, then:

$$
\begin{aligned}
& \dot{\mathrm{Q}}_{23}=-\dot{\mathrm{Q}}_{\mathrm{DA}} \\
& \dot{\mathrm{Q}}_{34}=-\dot{\mathrm{Q}}_{\mathrm{AB}}
\end{aligned}
$$

In Eq. (5) and Eq. (6), $\dot{Q}_{23}$ and $\dot{Q}_{34}$ are the heat absorbed by the air when it passes through the compressor and condenser, respectively. Then, the heat absorbed by the air between states 2 and 4 is:

$$
\begin{gathered}
\dot{\mathrm{Q}}_{24}=\dot{\mathrm{Q}}_{23}+\dot{\mathrm{Q}}_{34}=-\left(\dot{\mathrm{Q}}_{\mathrm{DA}}+\dot{\mathrm{Q}}_{\mathrm{AB}}\right)=-\dot{\mathrm{Q}}_{\mathrm{DB}} \\
\dot{\mathrm{Q}}_{24}=\dot{\mathrm{m}}_{\mathrm{R}-22}\left(\mathrm{~h}_{\mathrm{D}}-\mathrm{h}_{\mathrm{B}}\right)-\dot{\mathrm{W}}_{\mathrm{DA}}
\end{gathered}
$$

For the air process in V1, according to CM and FLT $(\Delta \mathrm{Ep} \cong 0$ and $\Delta \mathrm{Ek} \cong 0$, and stationary energy process):

$$
\begin{gathered}
\dot{\mathrm{m}}_{2}=\dot{\mathrm{m}}_{3}=\dot{\mathrm{m}}_{4} \\
\dot{\mathrm{Q}}_{24}=\dot{\mathrm{m}}_{4} \mathrm{~h}_{4}-\dot{\mathrm{m}}_{2} \mathrm{~h}_{2}=\dot{\mathrm{m}}_{2}\left(\mathrm{~h}_{4}-\mathrm{h}_{2}\right)
\end{gathered}
$$

In Eq. (10), $\mathrm{h}_{4}$ and $\mathrm{h}_{2}$ are the enthalpies of the air in the state 4 and 2, respectively. Considering V2, and applying $\mathrm{CM}$ and FLT to the air $(\Delta \mathrm{Ep} \cong 0, \Delta \mathrm{Ek} \cong$ $0)$ :

$$
\begin{gathered}
\dot{\mathrm{m}}_{1}=\dot{\mathrm{m}}_{2}+\dot{\mathrm{m}}_{5} \\
\dot{\mathrm{Q}}_{12}=\dot{\mathrm{m}}_{2} \mathrm{~h}_{2}+\dot{\mathrm{m}}_{5} \mathrm{~h}_{5}-\dot{\mathrm{m}}_{1} \mathrm{~h}_{1}
\end{gathered}
$$

Since the absolute humidity of air $(\omega)$ is defined as the quotient between the mass of water in vapor ( $\left.\dot{\mathrm{m}}_{\text {vap }}\right)$ states in the air and dry air $\left(\dot{\mathrm{m}}_{\mathrm{gas}}\right)$, then $\dot{\mathrm{m}}_{\mathrm{vap} 1}=\omega_{1} \dot{\mathrm{m}}_{\text {gas }}$ and $\dot{\mathrm{m}}_{\mathrm{vap} 2}=\omega_{2} \dot{\mathrm{m}}_{\text {gas }}$, which yields:

$$
\begin{gathered}
\dot{\mathrm{m}}_{5}=\dot{\mathrm{m}}_{1}-\dot{\mathrm{m}}_{2}=\dot{\mathrm{m}}_{\mathrm{gas}}\left(\omega_{1}-\omega_{2}\right) \\
\dot{\mathrm{m}}_{2}=\frac{\dot{\mathrm{m}}_{\mathrm{gas}}}{\left(1+\omega_{2}\right)}
\end{gathered}
$$

It is considered that the heat released by the evaporator $\left(\dot{\mathrm{Q}}_{\mathrm{CD}}\right)$ is absorbed by the air $\left(\dot{\mathrm{Q}}_{12}\right)$ :

$$
\dot{\mathrm{Q}}_{12}=-\dot{\mathrm{Q}}_{\mathrm{CD}}
$$

The COP of the heat pump is calculated by:

$$
\mathrm{COP}=\frac{\dot{\mathrm{Q}}_{\mathrm{DA}}+\dot{\mathrm{Q}}_{\mathrm{AB}}}{\dot{\mathrm{W}}_{\text {comp }}+\dot{\mathrm{W}}_{\mathrm{fan}}}=\frac{\dot{\mathrm{Q}}_{\mathrm{DB}}}{\dot{\mathrm{W}}_{\text {comp }}+\dot{\mathrm{W}}_{\mathrm{fan}}}
$$

The consideration expressed by Eq. (16) allows for the calculation of $\dot{\mathrm{m}}_{\mathrm{R}-22}$.

\section{RESULTS AND DISCUSSION}

The experimental setup suffered a series of changes throughout the process of data gathering. One of the issues encountered was the formation of ice on the expansion valve, which finally resulted in a location change for the temperature sensor (which was moved closer to the valve outlet). Another issue encountered after substitution of the compressor (the original equipment burnt when the heat pump was relocated) was that the temperatures measured at the outlet of the evaporator were actually lower than the temperatures at the inlet of the evaporator. This

\begin{tabular}{|c|c|c|c|c|}
\hline \multirow{2}{*}{\multicolumn{2}{|c|}{\begin{tabular}{c|} 
Area $\left(\mathrm{m}^{2}\right)$ \\
0.00785
\end{tabular}}} & \multicolumn{2}{|c|}{$\mathrm{R}(\mathrm{kJ} / \mathrm{Kg} \mathrm{K})$} & Velocity (m/s) \\
\hline & 1 & .287055 & & 6.9 \\
\hline \multicolumn{5}{|c|}{ Consumed power } \\
\hline \multicolumn{2}{|c|}{$\dot{\mathrm{W}}_{\text {comp }}=\dot{\mathrm{W}}_{\mathrm{DA}}(\mathrm{kJ} / \mathrm{s})$} & & \multicolumn{2}{|c|}{$\dot{\mathrm{W}}_{\mathrm{fan}}(\mathrm{kJ} / \mathrm{s})$} \\
\hline \multicolumn{2}{|c|}{0.940} & & \multicolumn{2}{|c|}{0.22917} \\
\hline \multicolumn{5}{|c|}{ Pressure } \\
\hline $\mathrm{P}_{0}(\mathrm{kPa})$ & \multicolumn{2}{|r|}{$\mathrm{P}_{\mathrm{A}}(\mathrm{kPa})$} & \multicolumn{2}{|c|}{$\mathrm{P}_{\mathrm{D}}(\mathrm{kPa})$} \\
\hline 101.325 & \multicolumn{2}{|r|}{3850} & \multicolumn{2}{|c|}{476} \\
\hline \multicolumn{5}{|c|}{ Temperature of the air } \\
\hline $\mathrm{T}_{0}(\mathrm{~K})=\mathrm{T}_{1}(\mathrm{~K})$ & $\mathrm{T}_{2}(\mathrm{~K})$ & $\mathrm{T}_{3}(\mathrm{~K})$ & $\mathrm{T}_{4}(\mathrm{~K})$ & $\mathrm{T}_{5}(\mathrm{~K})$ \\
\hline 302.8 & 288.0 & 295.8 & 322.0 & 294.0 \\
\hline \multicolumn{5}{|c|}{ Temperature of R-22 } \\
\hline $\mathrm{T}_{\mathrm{A}}(\mathrm{K})$ & $\mathrm{T}_{\mathrm{B}}(\mathrm{K})$ & \multicolumn{2}{|c|}{$\mathrm{T}_{\mathrm{C}}(\mathrm{K})$} & $\mathrm{T}_{\mathrm{D}}(\mathrm{K})$ \\
\hline 384.0 & 305.3 & \multirow{2}{*}{\multicolumn{2}{|c|}{$\begin{array}{l}276.7 \\
\text { Relative hut }\end{array}$}} & 277.4 \\
\hline \multicolumn{2}{|c|}{ Absolute humidity of air } & \multicolumn{2}{|c|}{ Relative humidity of air } & \\
\hline $\begin{array}{l}\omega_{1}\left(\mathrm{~kg}_{\mathrm{H} 2 \mathrm{O}}\right. \\
\left./ \mathrm{kg}_{\text {dryair }}\right)\end{array}$ & $\begin{array}{c}\omega_{2}\left(\mathrm{~kg}_{\mathrm{H} 2 \mathrm{O}}\right. \\
\left./ \mathrm{kg}_{\text {dryair }}\right)\end{array}$ & \multicolumn{2}{|c|}{$\phi_{1}(\%)$} & $\phi_{2}(\%)$ \\
\hline 0.01872 & 0.01620 & \multicolumn{2}{|c|}{71.3} & 22.1 \\
\hline
\end{tabular}
occurred due to incompatibility issues between the compressor and the expansion valve, which was then substituted.

The experiments were executed in different days between the months of May and September of 2014, which includes different temperatures and relative humidity. Air velocity varied to represent more variable conditions for the air. The most representative data was selected, which is shown in Table 1.

Table 1. Data obtained during experiments.

In Table 1 , the area (in $\mathrm{m}^{2}$ ) represents the area of the pipe line, $\mathrm{R}(\mathrm{kJ} / \mathrm{Kg} \mathrm{K})$ is the gas constant, Velocity $(\mathrm{m} / \mathrm{s})$ is the velocity of air, $\dot{\mathrm{W}}_{\text {comp }}$ is the power of the compressor (in $\mathrm{J} / \mathrm{s}$ ), $\dot{\mathrm{W}}_{\text {fan }}(\mathrm{kJ} / \mathrm{s}$ ) is the power of the fan, $\mathrm{P}_{0}(\mathrm{kPa})$ is the pressure for environmental (reference) conditions, $\mathrm{P}_{\mathrm{A}}(\mathrm{kPa})$ is the pressure at compressor output, $\mathrm{P}_{\mathrm{D}}(\mathrm{kPa})$ is the pressure at the compressor input, $\mathrm{T}_{0}$ through $\mathrm{T}_{5}$ are 
the different temperatures for air (in K) depending on location, $\mathrm{T}_{\mathrm{A}}$ through $\mathrm{T}_{\mathrm{D}}$ are the different temperatures for R-22 (in $\mathrm{K}$ ) depending on location, $\omega_{1}$ and $\omega_{2}$ are the absolute humidities of air $\left(\mathrm{kg}_{\text {H2O }} / \mathrm{kg}_{\text {dryair }}\right.$ ) depending on location and finally, the relative humidity of the air is given by $\phi_{1}(\%)$ and $\phi_{2}$ (\%). Absolute humidity was calculated from relative humidity values, using the Engineering Equation System (EES) (<http://www.fchart.com/ees/>. Accessed on 23 April, 2014).

The enthalpies of air and refrigerant (R-22) for the different locations from which data was collected are shown in Tables 2. These values were calculated by EES from temperature and pressure data.

Table 2. Properties of the air and refrigerant in different locations.

\begin{tabular}{|c|c|c|c|}
\hline Location & $\mathrm{h}(\mathrm{kJ} / \mathrm{kg})$ & Location & $\mathrm{h}(\mathrm{kJ} / \mathrm{kg})$ \\
\hline 1 & 77.65 & $\mathrm{~A}$ & 296.8 \\
\hline 2 & 55.87 & $\mathrm{~B}$ & 86.16 \\
\hline 3 & 63.95 & $\mathrm{C}$ & 86.16 \\
\hline 4 & 91.12 & $\mathrm{D}$ & 253.4 \\
\hline 5 & 87.18 & & \\
\hline
\end{tabular}

Finally, Table 3 shows the results obtained by the application of Eq. (1) through (16) in combination with data from Tables 1 and 2, using EES.

Table 3. Flow rates, heat rates, and COP for the heat pump.

\begin{tabular}{|c|c|c|c|c|}
\hline \multicolumn{5}{|c|}{ Flow rates $(\mathrm{kg} / \mathrm{s})$} \\
\hline$\dot{\mathrm{m}}_{1}$ & $\dot{\mathrm{m}}_{2}$ & $\dot{\mathrm{m}}_{5}$ & $\dot{\mathrm{m}}_{\text {gas }}$ & $\dot{\mathrm{m}}_{\mathrm{R}-22}$ \\
\hline 0.07137 & 0.07119 & 0.0001764 & 0.07006 & 0.00926 \\
\hline \multicolumn{5}{|c|}{ Heat transfer rates $(\mathrm{kJ} / \mathrm{s})$} \\
\hline$\dot{\mathrm{Q}}_{12}=-\dot{\mathrm{Q}}_{\mathrm{CD}}$ & $\dot{\mathrm{Q}}_{23}=-\dot{\mathrm{Q}}_{\mathrm{DA}} \dot{\mathrm{Q}}_{34}=-\dot{\mathrm{Q}}_{\mathrm{A}}$ & $\dot{\mathrm{Q}}_{24}=-\dot{\mathrm{Q}}_{\mathrm{DH}}$ \\
\hline-1.5490 & \multicolumn{5}{|c|}{0.5382} & 1.9510 & 2.5100 \\
\hline \multicolumn{5}{|c|}{ COP } \\
\hline
\end{tabular}

For the studied heat pump, the objective was to identify and add all energy components involved, including the heat rejected by the compressor shell as well as the energy rejected to condense water vapor in the evaporator, and divide the figure obtained by the consumed power. The COP value obtained in Table 3 (COP $=2.1470)$ considers both the compressor power and the fan power, for air velocity equal to $6.9 \mathrm{~m} / \mathrm{s}$.

For this heat pump, the locations from 1 to 4 represent the locations of the operational air currents, being locations 1 and 2, respectively, the inlet and outlet of the evaporator (dehumidification process). It is observed that after this point, the absolute humidity remains constant throughout the heating process (until location 4). A singularity of this heat pump is that between locations 2 and 3 (evaporator outlet and condenser inlet) the air absorbs the heat rejected by the compressor, rather than discharging it into the environment. Between locations 3 and 4 , the air absorbs the heat rejected by the condenser.

Another parameter that could be utilized to evaluate the heat pump studied herein is the specific moisture extraction rate (SMER), which is an indication of the energy required for the removal of moisture (Hawlader \& Jahangeer, 2012). SMER is expressed as the ratio of the moisture removed $(\mathrm{kg})$ to the energy input $(\mathrm{kJ})$. This corresponds to $\dot{\mathrm{m}}_{5}$ divided by $\dot{\mathrm{W}}_{\text {comp }}$, which yields $0.6754 \mathrm{~kg} / \mathrm{kJ}$. This value is apparently low, however the installation of a flow meter for R-22 would allow this value to be calculated with more precision, since it depends on the mass flow of condensed water $\left(\dot{\mathrm{m}}_{5}\right)$.

Analysis of the heat pump verifies that the device is technically viable and provides satisfactory operational conditions for the drying of biological products: air is heated to $48.8^{\circ} \mathrm{C}$ and dehumidified until a relative humidity of $22.1 \%$. No tests were carried out involving the drying of biological products at this stage, but the operational figures obtained herein agree with several studies on heat pump assisted dryers (Perera, Rahman, 1997; Sosle, 2002; Patel, Kar, 2012; Kivevele, Huan, 2014).

\section{CONCLUSIONS}

A computational program was written in the Engineering Equation System (EES) (<http://www.ni.com/labview/applications/instrument -control/pt/> Accessed on 02 October, 2014), which included the real values measured (pressure, speed, temperature) as well as the energy transfers occurring throughout the system. The aforementioned equations and control volumes were utilized in the EES model. Experimental data included air velocity, air temperature (ambient, and at locations 1, 2, 3, 4), power consumed by the compressor and fan, atmospheric pressure at locations A and D, R22 temperature (A, B, C and D), and relative ( $\phi_{1}$ and $\left.\phi_{2}\right)$ air humidities. Internal properties of EES allowed for calculation of entropy and enthalpy for air and R22 at each location, as well as of absolute humidity values $\left(\omega_{1}\right.$ and $\left.\omega_{2}\right)$.

Results obtained via EES, through solution of the system of equations, were mass flow (air, condensed water), heat transfer rates, and COP.

It was verified that the heat pump system is technically viable and provides very satisfactory results: air was heated to a temperature of $48.8^{\circ} \mathrm{C}$ and dehumidified to a $22.1 \%$ relative humidity. Different air speeds were tested, which did not influence significantly the COP of the system (average 2.1470).

Suggestions can be made at this point to improve the precision and reliability of data. The introduction of a flow meter in the pipe line would allow for the measurement of R-22 flow rates. As a consequence, heat transfer coefficients could be 
obtained for the heat transfer between the evaporator $\left(\dot{Q}_{C D}\right)$ and the air $\left(\dot{Q}_{12}\right)$ (rather than using this condition to determine the flow rate of R-22). Digital manometers could also be installed at the condenser outlet and evaporator inlet, obtaining also more precise data (rather than considering constant pressures between the inlets and outlets of the condenser and evaporator). Although this mentioned difference in pressure could not be significant, would return more precise pressure values in locations B and D.

An exergy analysis of the same system would take the analysis a step further by also considering the quality of the energy flows involved. More studies are suggested to be carried out, bringing together academics and industry, with the main goal to foster the wide-spread application of heat pump assisted dryers. Gradually, low-energy, low-carbon technologies will have to the employed to achieve primary energy savings and consequent avoided greenhouse gas emissions.

\section{REFERENCES}

Hawlader, M. N. A., and Jahangeer, K. A., 2012, Heat Pump Design for Food Processing, in: Ahmed, and J., Rahman, M. S. (eds.), 2012, Handbook of Food Process Design, John Wiley \& Sons, Ltd.

Aktaş, M., Ceylan, İ., and Yilmaz, S., 2009, Determination of Drying Characteristics of Apples in a Heat Pump and Solar Dryer, Desalination, Vol. 239, No. 1-3 , pp. 266-275.

Artnaseaw, A., Theerakulpisut, S., and Benjapiyaporn, C., 2010, Development of a Vacuum Heat Pump Dryer for Drying Chilli, Biosystems engineering, Vol. 105, No. 1, pp. 130-138.

Castell-Palou, A., and Simal, S., 2011, Heat Pump Drying Kinetics of a Pressed Type Cheese, Food Science and Technology, Vol. 44, No. 2, pp. 489-494.

Daghigh, R., Ruslan, M. H., Sulaiman, M. Y., and Sopian, K., 2010, Review of Solar Assisted Heat Pump Drying Systems for Agricultural and Marine Products, Renewable and Sustainable Energy Reviews, Vol. 14, No. 9, pp.2564-2579.

Fatouh, M., Metwally, M. N., Helali, A. B., and Shedid, M. H., 2006, Herbs Drying using a Heat Pump Dryer, Energy Conversion and Management, Vol. 47, No. 15-16, pp. 2629-2643.

Hii, C. L., Law, C. L., and Suzannah, S., 2012, Drying Kinetics of the Individual Layer of Cocoa Beans during Heat Pump Drying, Journal of Food Engineering, Vol. 108, No. 2, pp.276-282.

Kivevele, T., and Huan, Z., 2014, A Review on Opportunities for the Development of Heat Pump Drying Systems in South Africa, South African Journal of Science, Vol. 110, No. 5-6, pp. 1-11.

Luiz, M. R., 2007, Heat Pump for Air Desumidification and Heating, Master Thesis,
Federal University of Paraíba, João Pessoa, Paraíba, Brasil. (In Portuguese)

Patel, K. K., and Kar, A., 2012, Heat Pump Assisted Drying of Agricultural Produce - an Overview, Journal of Food Science and Technology, Vol. 49, No. 2, pp. 142-160.

Perera, C. O., and Rahman, M. S., 1997, Heat Pump Dehumidifier Drying of Food, Trends in Food Science \& Technology, Vol. 8, No. 3, pp. 75-79.

Sosle, V., 2002, A Heat Pump Dehumidifier Assisted Dryer for Agri-Foods, Doctoral Thesis, Department of Agricultural and Biosystems Engineering, McGill University, Montreal, Canada.

Yang, Z., Zhu, E., Zhu, Z., Wang, J., and Li, S., 2013, A Comparative Study on intermittent Heat Pump Drying Process of Chinese Cabbage (Brassica campestrisL.ssp) Seeds, Food and Bioproducts Processing, Vol. 91, No. 4, pp. 381-388. 